\title{
8
}
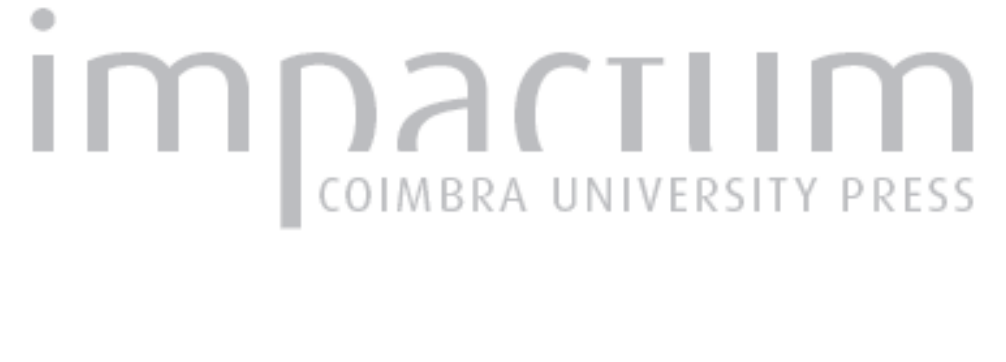

\section{Lesões e danos resultantes do emprego de meios coercivos pela Polícia de} Segurança Pública
Autor(es):
Rodrigues, E.; Magalhães, T.; Matos, E.
Publicado por: Imprensa da Universidade de Coimbra
URL persistente:
URI:http://hdl.handle.net/10316.2/33211
DOI:
DOI:http://dx.doi.org/10.14195/1647-8630_21_5

Accessed : $\quad$ 26-Apr-2023 07:56:45

A navegação consulta e descarregamento dos títulos inseridos nas Bibliotecas Digitais UC Digitalis, UC Pombalina e UC Impactum, pressupõem a aceitação plena e sem reservas dos Termos e Condições de Uso destas Bibliotecas Digitais, disponíveis em https://digitalis.uc.pt/pt-pt/termos.

Conforme exposto nos referidos Termos e Condições de Uso, o descarregamento de títulos de acesso restrito requer uma licença válida de autorização devendo o utilizador aceder ao(s) documento(s) a partir de um endereço de IP da instituição detentora da supramencionada licença.

Ao utilizador é apenas permitido o descarregamento para uso pessoal, pelo que o emprego do(s) título(s) descarregado(s) para outro fim, designadamente comercial, carece de autorização do respetivo autor ou editor da obra.

Na medida em que todas as obras da UC Digitalis se encontram protegidas pelo Código do Direito de Autor e Direitos Conexos e demais legislação aplicável, toda a cópia, parcial ou total, deste documento, nos casos em que é legalmente admitida, deverá conter ou fazer-se acompanhar por este aviso. 


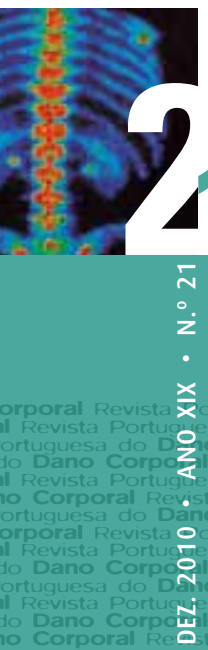

REVISTA PORTUGUESA

do

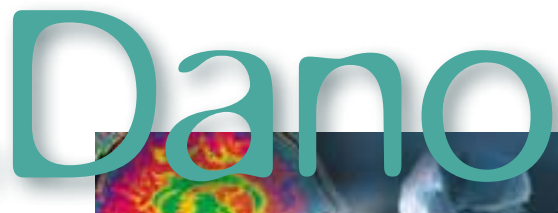

$\dot{z}$

$\dot{x}$

$\frac{x}{x}$

o. corporal Corporal Revista Portuguesa do Dano Corporal

Z

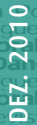

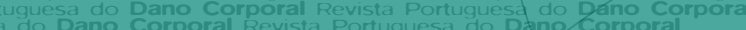

Revista Portuguesa do Dano Corporal Revista Rortuguesa do Dano Corporal

Sa do Dano Corporal Revista Portuguesa do Dano Corporal Revista Portuguesł do Dano Corporal

Portuguesa do Dano Corporal Revista portuguesta do Dano Corporal 


\title{
Lesões e danos resultantes do emprego de meios coercivos pela Polícia de Segurança Pública
}

\author{
E. Rodrigues ${ }^{1}$, T. Magalhães $2-5$, E. Matos 3
}

\section{Introdução}

A Constituição da República Portuguesa (CRP) estabelece como função fundamental da polícia "defender a legalidade democrática e garantir a segurança interna e os direitos dos cidadãos" (art. 272. ${ }^{\circ}$, n. ${ }^{\circ} 1$ ). No mesmo sentido, a orgânica da Polícia de Segurança Pública (OPSP) - aprovada pela Lei n. ${ }^{\circ}$ 53/2007, de 31 de Agosto - define como missão desta polícia "assegurar a legalidade democrática, garantir a segurança interna e os direitos dos cidadãos, nos termos da Constituição e da lei" (art. 1. ${ }^{\circ}$, n. $^{\circ} 1$ ).

A prossecução dos objectivos da actividade da polícia em geral, e da PSP em particular, por vezes, obriga a que os seus agentes recorram a meios coercivos. A Lei de Segurança Interna (LSI) - aprovada pela Lei n. ${ }^{\circ}$ 53/2008, de 04 de Setembro, rectificada pela Declaração de Rectificação n. ${ }^{\circ}$ 66-A/2008, de 28 de Outubro - estipula que os agentes das forças e dos serviços de segurança só podem utilizar meios coercivos "para repelir uma agressão actual e ilícita de interesses juridicamente protegidos, em defesa própria ou de terceiros" e "para vencer resistência à execução de um serviço no exercício das suas funções, depois de ter feito intimação formal de obediência e esgotados os outros meios para o conseguir" (art. 34. ${ }^{\circ}$, n. $^{\circ} 1$ ).

Relativamente aos meios coercivos concretamente utilizados pelos agentes da autoridade, destacam-se os seguintes: armas de fogo aptas a disparar projécteis letais (full metal jacket) ou menos letais (e.g., borracha); técnicas de defesa policial; algemas (metálicas ou de plástico); gases neutralizantes

\footnotetext{
Comando Metropolitano da Polícia de Segurança Pública do Porto

Delegação do Norte do Instituto Nacional de Medicina Legal, I.P.

Faculdade de Medicina da Universidade do Porto

Instituto Ciências Biomédicas Abel Salazar da Universidade do Porto

CENCIFOR - Centro de Ciências Forenses, Portugal
} 
(e.g., OCSpray); armas eléctricas; bastões (de metal, de borracha, de outros materiais); canhões de água; canídeos; lagartas metálicas para imobilização de viaturas. De entre estes meios, as armas de fogo constituem os mais perigosos. Por tal motivo, a lei - neste caso, o DL n. ${ }^{\circ} 457 / 99$, de 5 de Novembro - estabelece as circunstâncias e o modo específicos em que as mesmas podem ser utilizadas. Quanto aos restantes meios, a sua existência e o modo como os agentes devem utilizá-los não constam da lei. Na verdade, a escolha destes meios enquadra-se no âmbito da discricionariedade técnica da polícia, que pode definir, e define, normas internas específicas quanto ao seu modo de emprego.

$\mathrm{O}$ recurso a meios coercivos acarreta riscos para a integridade física e para a vida dos cidadãos visados. Estes riscos, por vezes, traduzem-se em lesões e danos de gravidade variável que, no limite, resultam na incapacidade (temporária ou permanente) (Magalhães, 2005) (Bessières-Roques, et al., 2001) ou na morte dos ofendidos.

A perigosidade inerente aos meios coercivos ao dispor dos agentes policiais justifica que haja uma avaliação formal da sua aplicação. Esta avaliação tem como fundamento o art. $271 .^{\circ}$, n. $^{\circ} 1$, da CRP. Este preceito fundamental determina que "Os funcionários e agentes do Estado e das demais entidades públicas são responsáveis civil, criminal e disciplinarmente pelas acções ou omissões praticadas no exercício das suas funções e por causa desse exercício de que resulte violação dos direitos ou interesses legalmente protegidos dos cidadãos...". O apuramento daquela responsabilidade é feito, nos âmbitos civil e criminal, pelos tribunais, no âmbito disciplinar, no caso concreto da PSP, a nível interno, pela própria polícia, a nível externo, pela Inspecção Geral da Administração Interna (IGAI).

A avaliação das circunstâncias em que as lesões e os danos são provocados, bem como da gravidade destes, pode implicar a intervenção dos peritos forenses: ao nível da clínica forense, na realização de exames e perícias que visam a "descrição e avaliação dos danos provocados na integridade psicofísica" dos ofendidos (Portaria n. ${ }^{\circ}$ 522/2007, de 30 de Abril, art. 12. ${ }^{\circ}$ ) (Magalhães, et al., 2003); ao nível da patologia forense, na realização de autópsia médico-legal para esclarecimento dos casos de "morte violenta ou de causa ignorada" (Lei n. ${ }^{\circ} 45 / 2004$, de 19 de Agosto, art. 18. ${ }^{\circ}$, n. ${ }^{\circ}$ 1) (Knight, 1996) (Calabuig, et al., 1998).

A análise feita pelo perito é vertida em relatório pericial (V. art. $157 .^{\circ}$, do Código do Processo Penal; art. 581. ${ }^{\circ}$, do Código do Processo Civil), realizado de acordo com os modelos aprovados pelo Instituto Nacional de Medicina Legal, I.P. (INML). Os modelos de patologia forense e de clínica forense contêm, entre outros conteúdos, informação acerca das regiões corporais afectadas, no que concerne, respectivamente, ao exame do hábito externo 
e do hábito interno e ao exame objectivo da vítima. No âmbito da clínica forense é ainda fornecida a avaliação da gravidade das lesões e das sequelas relacionadas com o evento.

\section{Objectivos}

O objectivo geral deste estudo consiste em determinar se as lesões corporais provocadas pelos agentes da PSP nos cidadãos são ou não proporcionais face ao perigo que as acções destes representam para eles ou para terceiros.

Os objectivos específicos são os seguintes:

a) Caracterizar os cidadãos que foram vítimas de homicídio ou de ofensas à integridade física em consequência da utilização de meios coercivos pelos agentes da PSP;

b) Caracterizar os agentes da PSP a quem foram imputados crimes de homicídio e de ofensas à integridade física, no exercício das suas funções;

c) Identificar as circunstâncias em que os agentes da PSP causaram lesões aos cidadãos, nomeadamente, quanto ao perigo enfrentado e ao tipo de meio coercivo utilizado;

d) Descrever as lesões e os danos corporais resultantes para os cidadãos;

e) Avaliar o nível de responsabilidade penal, civil e disciplinar para os agentes da PSP julgados por homicídio e por ofensas à integridade física de cidadãos.

\section{Material e métodos}

Foi realizado um estudo retrospectivo a partir da análise das decisões judiciais de processos-crime instaurados contra agentes da Polícia de Segurança Pública, por homicídio e por ofensas à integridade física.

A partir de uma listagem fornecida pela Procuradoria-Geral da República (PGR), constituída por 191 processos-crime (19 por homicídio e 172 por ofensas à integridade física), foi estabelecida uma amostra de 96 processoscrime (18 por homicídio e 78 por ofensas à integridade física), instaurados entre 1991 e 2004. Considerando que, em alguns daqueles processos, existia mais do que um agente policial arguido ou mais do que um cidadão ofendido, obtiveram-se 113 casos (19 de homicídio e 94 de ofensas à integridade física), cada um formado pelo binómio "polícia-ofendido". 
Os processos-crime foram consultados, presencialmente, em tribunais judiciais de Portugal Continental, após solicitação postal dirigida aos respectivos Juízes-Presidentes. Consideraram-se os critérios de inclusão seguintes: (a) os processos-crime tinham como arguidos agentes da PSP; (b) os factos imputados aos agentes foram cometidos em situações de serviço; (c) os crimes atribuídos foram homicídio ou ofensas à integridade física; (d) os processos-crime atingiram a fase de audiência de julgamento.

A descrição da gravidade das lesões foi feita de acordo com os graus seguintes (Magalhães, 2005):

a) Grau 0 - ausência de lesões;

b) Grau 1 - lesões mínimas (ex: escoriações, soluções de continuidade superficiais);

c) Grau 2 - lesões de importância média (ex: laceração, fractura sem necessidade de tratamento cirúrgico);

d) Grau 3 - lesões importantes (implicam tratamento cirúrgico);

e) Grau 4 - lesões muito importantes (potencialmente letais).

A gravidade das sequelas foi medida de acordo com a escala proposta no "Inventário de Avaliação do Dano Corporal" (Magalhães, 1998) (Tabela 1).

Tabela 1. Gravidade das sequelas

\begin{tabular}{lc}
\hline \multicolumn{1}{c}{ Sequelas lesionais } & Sequelas funcionais e situacionais \\
\hline 0 - sem sequelas & 0 - sem dificuldades \\
\hline 1 - sequelas mínimas & 1 - dificuldades mínimas (lentidão, desconforto) \\
\hline 2 - sequelas de importância média & $\begin{array}{c}2-\text { dificuldades médias (ajuda técnica ou medicamentosa } \\
\text { ou adaptação do meio) }\end{array}$ \\
\hline 3 - sequelas importantes & $\begin{array}{c}3 \text { - dificuldades importantes (ajuda humana parcial ou } \\
\text { reconversão profissional) }\end{array}$ \\
\hline 4 - sequelas muito importantes & $\begin{array}{c}4 \text { - impossibilidade ou ajuda humana total (de subs- } \\
\text { tituição) }\end{array}$ \\
\hline
\end{tabular}

Os dados recolhidos nos processos foram tratados estatisticamente através do software SPSS 13.0 para Windows. Na análise dos dados foram utilizadas técnicas de estatística descritiva e de estatística inferencial. $\mathrm{Na}$ análise descritiva, de forma a evitar enviesamentos, não foram considerados os casos em que a percentagem de não respostas foi superior a 20\% (Pestana, et al., 2003). A análise da relação entre variáveis foi baseada no teste não paramétrico do Qui-Quadrado de Pearson $\left(\chi^{2}\right)$ ou, em alternativa, no Teste Exacto de Fisher (TEF), tendo sido estabelecido um nível de significância de 5\% (Pestana, et al., 2003) (Ramalheira, et al., 1995). 


\section{Resultados}

\section{Caracterização dos ofendidos e dos agentes policiais}

A maioria dos cidadãos ofendidos era do sexo masculino (92\%), com uma média de idade de 30.92 anos ( $\mathrm{DP}=10.879)$, solteiros (56.6\%) e com ocupação profissional (69\%). Os agentes policiais eram quase exclusivamente do sexo masculino (98.2\%), com idade média de 35.37 anos ( $\mathrm{DP}=6.914)$, casados (79.6\%), e pertenciam, maioritariamente, ao posto de Agente da PSP (82.3\%).

\section{Caracterização das circunstâncias em que ocorreram as lesões}

No que concerne às circunstâncias em que ocorreram as lesões, apurouse o seguinte: verificaram-se mais no ano de 2003 (22.12\%), nos distritos de Lisboa (28.3\%) e Porto (23\%), nos períodos $19 \mathrm{~h} 01-01 \mathrm{~h} 00$ (40.7\%) e 01h0107h00 (32.7\%); evidenciou-se a percentagem em que ocorreram como forma de represálias sobre os ofendidos (27.4\%), estando estes estáticos (38.1\%), em frente ao agente (44.25\%); os mecanismos de produção das lesões mais frequentes foram murros $(27.8 \%)$, disparos com projécteis letais $(19.6 \%)$, pontapés (15.5\%), bofetadas (13.4\%) e impactos com bastão policial (13.4\%); os factos decorreram, maioritariamente, na via pública (64.6\%); a acção dos ofendidos foi, mais frequentemente (36.3\%), de desrespeito às ordens dos agentes policiais; a reacção dos agentes face à acção dos ofendidos, na maioria dos casos $(62.8 \%)$, representou perigo de ofensa grave à integridade física ou perigo de morte.

\section{Descrição médico-legal das lesões e dos danos}

Relativamente às regiões corporais atingidas com maior gravidade, destacaram-se: a face (38.9\%), o crânio (18.6\%) e o tórax (15.9\%) (Gráfico 1).

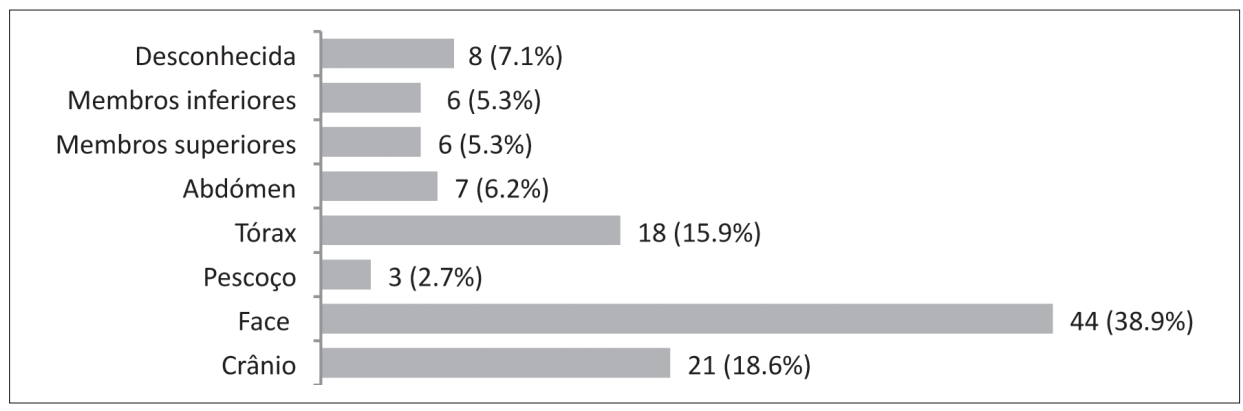

Gráfico 1. Região corporal atingida com maior gravidade 
No respeitante à gravidade das lesões mais importantes, foi de grau 1 em $38.1 \%$ dos casos, de grau 2 em $27.4 \%$ e de grau 5 em $12.4 \%$ (Tabela 2).

Tabela 2. Gravidade das lesões mais importantes $(n=113)$

\begin{tabular}{lcc}
\hline Gravidade & $\mathrm{n}$ & $\%$ \\
\hline Grau 0 & 7 & 6.2 \\
Grau 1 & 43 & 38.1 \\
Grau 2 & 31 & 27.4 \\
Grau 3 & 6 & 5.3 \\
Grau 4 & 4 & 3.5 \\
Grau 5 & 14 & 12.4 \\
Desconhecida & 8 & 7.1 \\
\hline
\end{tabular}

Quanto à gravidade das sequelas, constatou-se que, na maioria dos casos, foi de grau 0 , respectivamente, $77.9 \%$ para as sequelas lesionais, $79.6 \%$ para as sequelas funcionais e, igualmente, $79.6 \%$ para as sequelas situacionais (Tabela 3).

Tabela 3. Gravidade das sequelas $(n=113)$

\begin{tabular}{lcccccc}
\hline \multirow{2}{*}{ Gravidade } & \multicolumn{7}{c}{ Sequelas } \\
\cline { 2 - 7 } & \multicolumn{2}{c}{ Lesionais } & \multicolumn{2}{c}{ Funcionais } & \multicolumn{2}{c}{ Situacionais } \\
\cline { 2 - 8 } & $\mathrm{n}$ & $\%$ & $\mathrm{n}$ & $\%$ & $\mathrm{n}$ & $\%$ \\
\hline Grau 0 & 88 & 77.9 & 90 & 79.6 & 90 & 79.6 \\
\hline Grau 1 & 1 & 0.9 & 1 & 0.9 & 1 & 0.9 \\
\hline Grau 2 & 3 & 2.7 & 1 & 0.9 & 1 & 0.9 \\
\hline Grau 3 & 2 & 1.8 & 0 & 0.0 & 0 & 0.0 \\
\hline Grau 4 & 0 & 0 & 0 & 0.0 & 0 & 0.0 \\
\hline Desconhecida & 19 & 16.8 & 21 & 18.6 & 21 & 18.6 \\
\hline
\end{tabular}

\section{Análise das decisões judiciais}

Do total dos 113 casos estudados, em 61 casos (54\%) os agentes foram absolvidos e em 52 (46\%) foram condenados (Gráfico 2). De entre os casos de condenação, $11(21.15 \%)$ foram-no pelo crime de homicídio e $41(78.85 \%)$ pelo crime de ofensas à integridade física (Gráfico 2). Dentro destes tipos de crime, nos casos de homicídio, ocorreram 7 (63.3\%) condenações por homicídio por negligência, 3 (27.3\%) por homicídio simples e $1(9.1 \%)$ por homicídio qualificado; nos casos de ofensas à integridade física, ocorreram $34(82.9 \%)$ condenações por ofensa à integridade física simples e 7 (17.1\%) por ofensa à integridade física qualificada. 


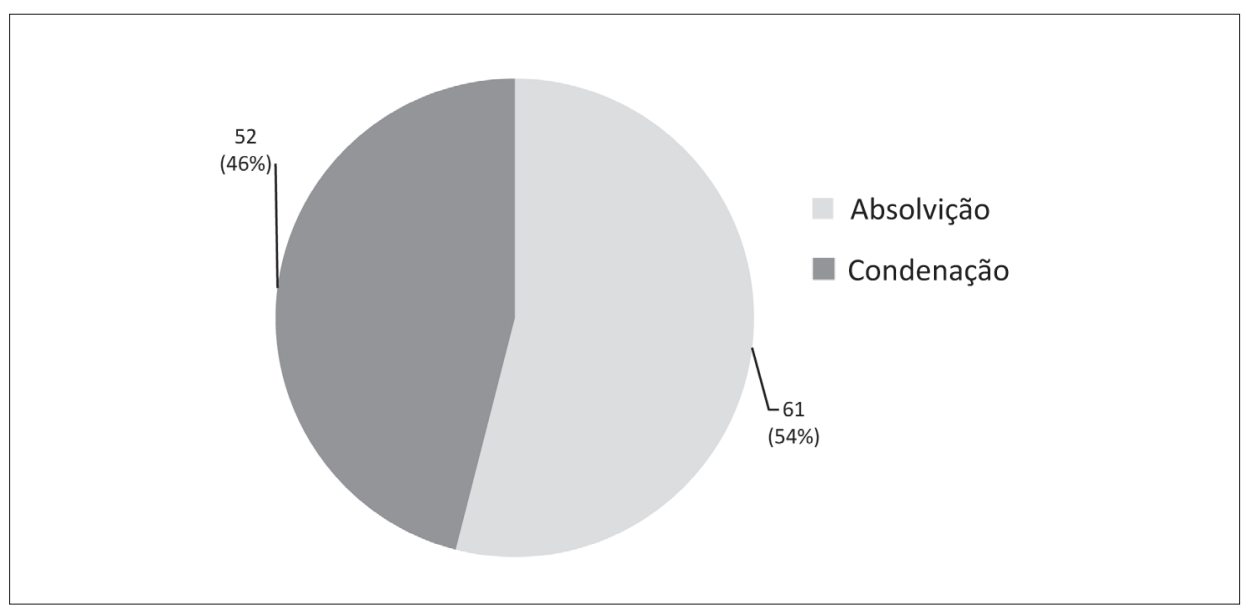

Gráfico 2. Resultado das decisões judiciais no âmbito criminal

No âmbito cível, em 63 (55.8\%) dos 113 casos estudados foi feito pedido de indemnização pelos danos decorrentes das lesões. Foi decretada judicialmente a obrigatoriedade de indemnizar em 32 casos, 4 por danos patrimoniais, 14 por danos não patrimoniais e 14 pelos dois tipos de danos. A obrigação de indemnizar recaiu sobre o agente policial em 30 casos (93.8\%). Os montantes de indemnização foram: mínimo - 50€; máximo - $75000 €$ média - 5403€ (DP=13 896).

\section{Estudo da relação de dependência entre variáveis}

Avaliou-se a relação entre variáveis, nos casos em que se considerou ser pertinente para o enriquecimento do estudo.

Verificou-se não existir uma relação estatisticamente significativa entre as variáveis seguintes: idade do agente policial e mecanismos de produção das lesões ( $p>0.05)$; idade do agente policial e região corporal com a lesão mais grave $\left(\chi^{2}=1.137 ; \mathrm{p}=0.566\right)$; idade do agente policial e gravidade das lesões $\left(\chi^{2}=1.43 ; \mathrm{p}=0.232\right)$; idade do agente policial e sentença penal $\left(\chi^{2}=1.236\right.$; $\mathrm{p}=0.266)$; perigo enfrentado pelo agente policial e gravidade das lesões mais importantes $\left(\chi^{2}=4.376 ; \mathrm{p}=0.112\right)$; realização de disparo de arma de fogo com projéctil letal e sentença penal $\left(\chi^{2}=0.957 ; \mathrm{p}=0.328\right)$; gravidade das lesões mais importantes e sentença penal $\left(\chi^{2}=1.167 ; \mathrm{p}=0.28\right)$.

Constatou-se existir uma relação estatisticamente significativa entre variáveis, nos termos seguintes: a produção de lesões através do mecanismo murro é semelhante no Norte (31.43\%), no Centro (35.29\%) e no Alentejo e Algarve $(32.0 \%)$ e diminuta em Lisboa $(6.25 \%)\left(\chi^{2}=8.434 ; \mathrm{p}=0.038\right)$; a maior percentagem 
de condenações do agente policial no âmbito penal ocorreu na zona Alentejo e Algarve $(72 \%)$ e a menor na zona Lisboa $(65.62 \%)\left(\chi^{2}=9.285 ; \mathrm{p}=0.026\right)$; a produção de lesões através do mecanismo disparo de arma de fogo com projéctil letal ocorreu mais às distâncias [0 - 1] metros (38.89\%) e [5 - 10] metros $(27.78 \%)$ $\left(\chi^{2}=56.305 ; \mathrm{p}<0.001\right)$; o agente policial utilizou quase em exclusivo $(97.14 \%)$ meios coercivos que representam perigo de ofensa grave à integridade física ou perigo de morte quando o ofendido não desenvolveu nenhuma acção contra ele ou contra terceiros $\left(\chi^{2}=18.796 ; \mathrm{p}<0.001\right)$; nos casos em que o mecanismo utilizado foi o disparo de arma de fogo com projéctil letal, as lesões provocadas foram, maioritariamente, de grau 4 e de grau $5(88.89 \%)\left(\chi^{2}=71.186 ; \mathrm{p}<0.001\right)$; nos casos em que o mecanismo utilizado foi o murro, as lesões foram de grau 3 ou inferior $\left(\chi^{2}=7.477 ; \mathrm{p}=0.005\right)$; a zona corporal mais visada com o disparo de arma de fogo com projéctil letal foi a do tórax/abdómen (44.0\%), não tendo sido visados os membros superiores nem os membros inferiores $\left(\chi^{2}=18.417\right.$; $\mathrm{p}<0.001$ ); o agente policial empregou meios coercivos que representam perigo de ofensa grave à integridade física ou perigo de morte em $94.12 \%$ dos casos em

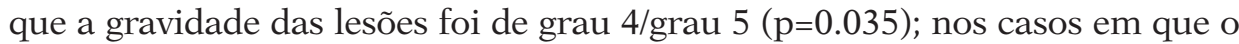
mecanismo utilizado foi a bofetada, houve mais condenações $(21.15 \%)$ do que absolvições $(3.51 \%)$ do agente $\left(\chi^{2}=8.06 ; \mathrm{p}=0.005\right)$; na grande maioria dos casos em que houve condenação por homicídio (90.91\%), o mecanismo utilizado foi o disparo de arma de fogo com projéctil letal $\left(\chi^{2}=45.895 ; \mathrm{p}<0.001\right)$; a decisão judicial penal foi, maioritariamente, de condenação do agente policial $(80.56 \%)$ quando a acção do visado não representou qualquer perigo para ele ou para terceiros, tendo sido de absolvição na maioria dos casos em que aquela acção representou este perigo $(84.62 \%)$ ou perigo de ofensa simples para a integridade física do agente ou de terceiros $(59.62 \%)\left(\chi^{2}=21.58 ; \mathrm{p}<0.001\right)$; quando o agente policial empregou meios coercivos que representam perigo de ofensa grave à integridade física ou de morte, ocorreu, maioritariamente, a sua condenação judicial penal (64.79\%), tendo prevalecido a absolvição (78.75\%) quando os meios utilizados representam apenas o perigo de ofensa à integridade física simples $(\chi=15.14 ; \mathrm{p}<0.001)$; a condenação judicial penal do agente pelo crime de ofensas à integridade física verificou-se mais quando os meios coercivos utilizados eram idóneos a provocar ofensa grave à integridade física ou morte $(50.7 \%)$.

\section{Discussão}

O presente estudo permitiu demonstrar que os mecanismos de produção das lesões mais frequentemente utilizados foram mecanismos contundentes: murros $(27.8 \%)$, disparos de arma de fogo com projéctil letal (19.6\%), pontapés 
(15.5\%), bofetadas (13.4\%) e impactos com bastão policial (13.4\%). Estes resultados são coerentes com os verificados para a zona corporal em que foi detectada a lesão mais grave: a face (38.9\%) e o tronco (22.1\%) (considerando o tórax e o abdómen em conjunto). A defesa desta coerência reside no facto de o murro ser geralmente desferido na face, por ser a parte para a qual os agentes policiais dirigem o olhar nas situações de confronto, e por os disparos de armas de fogo, usualmente, visarem o tronco, por esta ser uma zona ampla do corpo e, consequentemente, ser menos provável falhar o disparo, contrariamente ao que acontece, por exemplo, com os membros, os quais, neste estudo, nunca foram atingidos com disparos.

Quanto à gravidade das lesões mais severas, apesar de se ter constatado que o grau mais frequente foi o grau 1 (38.1\%), verificou-se que de entre todos os casos em que houve a execução de um disparo com projéctil letal, $84.2 \%$ deles originaram lesões de grau 4 e de grau 5, tendo os restantes $(15.8 \%)$ provocado lesões de grau igual ou inferior a 3. Este era um resultado esperado, atendendo às potencialidades lesivas de um projéctil disparado por arma de fogo. Tal expectativa tornou-se ainda mais elevada pelo facto de a zona corporal mais atingida com os disparos (tórax/abdómen) alojar órgãos cuja lesão pode implicar a morte (grandes vasos, pulmões, coração, fígado, baço, rins e tubo digestivo). Vários estudos anteriormente realizados comprovam igualmente a letalidade dos disparos de armas de fogo: Thomas Feltes (Feltes, 2003) verificou que os agentes policiais alemães provocaram a morte através de disparo de arma de fogo a 6 cidadãos em 2000, a 5 em 2001 e a 6 em 2003; Duncan Gear (Gear, 2003) apurou que, em Inglaterra e no País de Gales, entre 1997 e 2002, a polícia provocou a morte ou lesões físicas em 24 cidadãos para os quais efectuou disparos; Charles Diaz (Diaz, 2003) constatou que a polícia francesa, entre 1988 e 1992, provocou a morte a 57 cidadãos através de recurso a arma de fogo, e entre 1995 e 1999 efectuou disparos com armas de fogo contra pessoas em 102 casos, tendo provocado 20 mortos.

Considerando as sequelas resultantes do emprego de meios coercivos, importa antes de mais frisar que a terminologia usada neste estudo praticamente não foi verificada nos processos-crime consultados. Por isto, foi necessário anotar a descrição feita pelo tribunal e só posteriormente concretizar a sua classificação por graus com a ajuda de um perito médico. Para além dos casos em que era feita referência expressa no processo acerca da inexistência de sequelas, considerou-se o grau 0 também nos casos em que nada era referido acerca das mesmas, com o pressuposto de que se nada constava era porque não existia. Considerou-se desconhecida a gravidade das sequelas quando este desconhecimento era referido expressamente pelo tribunal. Atendendo a estas ressalvas, é importante ler com reservas 
os resultados obtidos (grau 0 na maioria dos casos, para todos os tipos de sequelas - lesionais [77.9\%], funcionais [79.6\%], situacionais [79.6\%]), em virtude de ficar a dúvida sobre se as sequelas não existiram realmente ou se apenas não foram consideradas pelo tribunal.

Relativamente ao coeficiente de dano, na análise dos processos-crime não foi encontrada qualquer referência sobre ele. De igual modo, afigurouse inviável fazer o seu apuramento através da conjugação dos resultados verificados para as sequelas, pelo que, embora tenha constituído um dos objectivos específicos deste estudo, não foi possível apresentar resultados. Esta impossibilidade ocorreu também ao nível do cálculo dos períodos de incapacidade para os ofendidos, essencialmente porque as referências feitas sobre estas variáveis nos processos-crime não existiam ou eram demasiado vagas. Em muitos processos nada era referido acerca da existência ou não da incapacidade de trabalho, apesar de, atendendo à gravidade das lesões e das sequelas, ser de prever que essa incapacidade se verificou, pelo menos temporariamente. Em particular, quanto à incapacidade permanente, sendo esta traduzida, não em lapsos temporais mas sim em percentagens, não tendo sido verificada qualquer avaliação deste tipo (por se estar em sede de direito penal e não cível), tornou-se impossível fazer o seu cálculo. Nos casos em que era feita referência à incapacidade para o trabalho, não só não era especificado o tipo de trabalho - geral ou profissional - como também nada era dito acerca do facto de a incapacidade ser total ou parcial.

No que concerne à avaliação da proporcionalidade com que os agentes policiais aplicaram os meios coercivos, ela foi baseada, essencialmente, na análise das percentagens de condenações e de absolvições judiciais penais, pelo facto de os tribunais serem a instância por excelência de controlo formal da actividade policial. Considerando que se verificaram 54\% de absolvições - mesmo que, maioritariamente, por não produção/insuficiência de prova sobre os factos imputados - e 46\% de condenações, pode afirmar-se que, na maioria dos casos, existiu proporcionalidade entre o perigo representado pelos cidadãos e as lesões e danos provocadas pelos agentes. Ao estudar-se a relação da decisão judicial no âmbito penal com o perigo representado pelos cidadãos e com a reacção dos agentes, verificou-se o seguinte: foi maioritariamente decretada a condenação nos casos em que a acção dos cidadãos não representou qualquer perigo $(80.56 \%)$ e em que a reacção dos agentes representou perigo de ofensa grave à integridade física ou de morte dos cidadãos (64.79\%); foi maioritariamente decidida a absolvição nos casos em que a acção dos cidadãos representou um perigo máximo de ofensa à integridade física simples (59.62\%) e nos casos em que aquela acção constituiu perigo de ofensa grave à integridade física ou de morte dos agentes ou de terceiros (84.62\%). Analisando a relação do tipo de crime imputado com a 
decisão judicial, de onde resulta que em 11 (57.9\%) dos 19 casos em que o crime imputado aos agentes foi homicídio, houve a condenação dos agentes policiais e que em 41 (43.62\%) dos restantes 94 casos, houve a condenação por ofensas à integridade física, pode dizer-se que na maioria dos casos em que o crime foi o homicídio não houve proporcionalidade na acção dos agentes e que essa proporcionalidade existiu na maioria dos casos em que o crime imputado foi ofensas à integridade física.

Ao nível da responsabilidade civil pelos danos decorrentes das lesões, de salientar a diferença entre o número de casos em que houve condenação ao nível penal $(\mathrm{n}=52)$ e o número de casos em que foi decretada a obrigatoriedade de indemnizar $(n=32)$, correspondendo a $61.54 \%$ de condenações cíveis na totalidade das condenações penais.

Quanto à responsabilidade disciplinar dos agentes policiais, não foi possível estudá-la, por impossibilidade de estabelecer a correspondência entre os referenciados no Gabinete de Deontologia e Disciplina da Direcção Nacional da PSP, em virtude de se utilizarem numerações independentes. De qualquer modo, foi possível apurar junto daquele Gabinete o registo da instauração de 62 processos por homicídio e 2027 por ofensas à integridade física, entre 1997 e 2004. De entre os processos por homicídio concluídos $(n=41)$, foram decretados $30(73.17 \%)$ arquivamentos e 11 (26.83\%) condenações. Quanto aos processos por ofensas à integridade física findos $(n=1494)$, foram decretados $1456(97.46 \%)$ arquivamentos e 38 (2.54\%) condenações.

\section{Conclusões}

A análise dos resultados obtidos através do estudo de 113 casos de lesões causadas por elementos da Polícia de Segurança Pública (PSP) acusados de homicídio ou de ofensas à integridade física permitiu concluir o seguinte:

1. Os cidadãos ofendidos eram maioritariamente do sexo masculino (92\%), com uma média de idades de 30.92 anos, solteiros (56.6\%) e com ocupação profissional (69\%);

2. Os agentes policiais eram quase exclusivamente do sexo masculino (98.2\%), com uma média de idades de 35.37 anos, casados (79.6\%) e pertenciam à carreira de Agente da PSP (82.3\%);

3. As lesões ocorreram maioritariamente no período compreendido entre as $19 \mathrm{~h} 00$ e as $07 \mathrm{~h} 00$ (73.4\%), na via pública (64.6\%), quando os ofendidos desenvolviam agressões físicas contra o(s) agente(s) policial(ais) ou terceiro(s) (21.2\%); 
4. Os agentes policiais concretizaram as lesões exercendo represálias sobre o(s) ofendido(s) (27.4\%), utilizando mais frequentemente como mecanismos de produção das lesões murros (27.8\%), disparos de armas de fogo com projécteis letais (19.6\%), pontapés (15.5\%), bofetadas (13.4\%) e impactos com bastão policial (13.4\%);

5. As lesões foram maioritariamente provocadas quando os ofendidos estavam estáticos $(38.1 \%)$, na posição de pé e de frente para o(s) agente(s) policial(ais) (44.25\%), a uma distância máxima de 1 metro $(78.8 \%)$;

6. A acção dos cidadãos representou com mais frequência o simples não acatamento de ordens (36.3\%), tendo os agentes policiais utilizado maioritariamente meios coercivos susceptíveis de provocar ofensa grave à integridade física ou a morte (62.8\%);

7. As zonas corporais mais frequentemente atingidas foram, por ordem decrescente, a face (38.9\%), o crânio (18.6\%) e o tórax (15.9\%);

8. Nos casos de disparo de arma de fogo com projéctil letal, a zona corporal mais frequentemente atingida foi o tórax/abdómen (44\%);

9. As lesões mais frequentemente provocadas foram de grau 1 (38.1\%);

10. As lesões provocadas por disparo de arma de fogo com projéctil letal foram maioritariamente de grau 4 e 5 (88.89\%);

11. As lesões provocadas através de murro foram sempre de grau igual ou inferior a 3;

12. As sequelas (lesionais, funcionais e situacionais) decorrentes das lesões provocadas pelos agentes policiais foram maioritariamente de grau 0 $(77.9 \%)$;

13. Na maioria dos casos estudados (54\%), os agentes policiais foram absolvidos, sendo a causa mais frequente de absolvição a não produção/insuficiência de provas sobre os factos que lhes foram imputados $(50.8 \%)$;

14. Na maioria dos casos estudados houve dedução de pedido de indemnização cível (55.8\%) e, de entre estes, foi maioritariamente decretada a obrigação de indemnizar (50.8\%), sendo esta maioritariamente incumbida ao agente policial agressor (93.8\%);

15. Atendendo unicamente à percentagem de condenações verificadas nos 113 casos estudados (46\%), pode afirmar-se que os agentes da PSP provocaram lesões nos cidadãos, maioritariamente, de modo proporcional ao perigo por eles representado; 
16. Analisando cada um dos crimes em particular, nos casos de homicídio (19), a percentagem de condenações foi de 57.9\%, nos casos de ofensas à integridade física (94), essa percentagem foi de $43.62 \%$, podendo por isso afirmar-se que as lesões provocadas pelos agentes foram maioritariamente proporcionais nos casos em que o crime imputado ao agente foi ofensas à integridade física e desproporcionais nos casos de homicídio;

17. Tendo em conta o facto de nos casos de homicídio ocorrer maioritariamente a condenação do agente policial, afigura-se pertinente que a Polícia de Segurança Pública invista de modo especial na formação contínua dos seus efectivos ao nível da utilização dos meios coercivos susceptíveis de provocar a morte, em particular ao nível dos aspectos legais do uso de armas de fogo.

\section{Referências bibliográficas}

Bessières-Roques I, Fournier C, Huges-Béjui H, et al. Précis d'évaluation du dommage corporel. 2. ${ }^{e}$ ed. Paris: Largus; 2001. p. 169-189.

Calabuig G, Pascual. Autópsia médico-legal. In: Calabuig G, editor. Medicina Legal y Toxicologia. Barcelona: Masson; 1998. p. 219.

Diaz C. O uso de armas de fogo pelos agentes policiais em França. In: Inspecção Geral da Administração Interna, editor. Uso de armas de fogo pelos agentes policiais. Lisboa: IGAI; 2004. p. 61-71.

Feltes T. O uso de armas de fogo pelos agentes policiais na Alemanha. In: Inspecção Geral da Administração Interna, editor. O uso de armas de fogo pelos agentes policiais. Lisboa: IGAI; 2004. p. 13-29.

Gear D. O uso de armas de fogo por agentes policiais: a abordagem em Inglaterra e País de Gales. In: Inspecção Geral da Administração Interna. Uso de armas de fogo pelos agentes policiais. Lisboa: IGAI; 2003. p. 31-48.

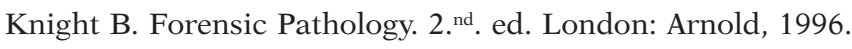

Magalhães T, Costa D, Real FC, et al. Avaliação do dano corporal em direito penal: breves reflexões médico-legais. Revista de Direito Penal 2003; 2(1): 6-82.

Magalhães T. Estudo Tridimensional do Dano Corporal: Lesão, Função e Situação (Sua Aplicação Médico-Legal). Coimbra: Coimbra Editora; 1998. p. 94-100.

Pestana M, Gageiro J. Análise de dados para Ciências Sociais: a complementaridade do SPSS. Lisboa : Edições Sílabo; 2003. p. 62-100.

Ramalheira A, Cardoso S. A caracterização do risco: risco relativo e odds ratio como medidas do grau de associação entre factores e doença. Coimbra: Coimbra Editora; 1995. p. 139-140. 
Resumo: Lesões e danos resultantes do emprego de meios coercivos pela Polícia de Segurança Pública

0 âmbito deste estudo respeita aos crimes de homicídio e de ofensas à integridade física imputados a agentes da Polícia de Segurança Pública (PSP) no exercício das suas funções, entre os anos 1991 e 2004.

Com a sua realização pretendeu-se apurar se as lesões causadas pelos agentes policiais foram proporcionais ao perigo representado pela acção dos cidadãos ofendidos. Visou-se ainda caracterizar os ofendidos, os agentes policiais agressores e as circunstâncias em que as lesões foram provocadas, bem como descrever as lesões e as sequelas resultantes dessas lesões e apurar o nível de responsabilidade penal, cível e disciplinar dos agentes ofensores. Para alcançar estes objectivos, foram analisadas as decisões judiciais de 96 processos-crime instaurados contra agentes da PSP por homicídio ou por ofensas à integridade física. A partir destes 96 processos obtiveram-se 113 casos, cada um constituído pelo binómio “polícia ofendido".

A recolha de dados foi realizada em vários tribunais de Portugal Continental nos quais, através de informação da Procuradoria-Geral da República, foi possível localizar os processoscrime. Os dados foram colhidos numa ficha em que constavam as variáveis com interesse para o estudo. A análise estatística foi feita utilizando o software Statistical Package for the Social Sciences (SPSS), versão 13.0.

Apurou-se que os cidadãos ofendidos eram maioritariamente do sexo masculino, jovens, solteiros e tinham actividade profissional. Verificou-se que as lesões foram maioritariamente provocadas por elementos policiais da classe de Agente, de noite, na via pública, através de murros, pontapés, bofetadas, disparos de arma de fogo com projéctil letal e impactos com o bastão policial, e que o perigo representado pela acção dos cidadãos foi a colaboração com os agentes e a reaç̧ão destes proporcionou perigo de ofensa grave à integridade física ou perigo de morte. Constatou-se que a zona corporal mais atingida foi a face, que a gravidade das lesões mais frequente foi de grau 1 e a gravidade das sequelas de grau 0 . A decisão judicial no âmbito penal, na maioria dos casos (54\%), foi a absolvição. De igual modo, no âmbito cível, a decisão maioritária foi a não obrigatoriedade de indemnizar.

Analisando a relação entre o perigo representado pela acção dos cidadãos e a reacção dos agentes policiais, concluiu-se que esta foi maioritariamente desproporcional quando aquele perigo foi nulo ou apenas representou a não colaboração ou a possibilidade de ocorrência de ofensa simples à integridade física e foi proporcional quando representou perigo de ofensa grave à integridade física ou perigo de morte.

Considerando somente os resultados da decisão judicial no âmbito penal, verificou-se que na maior parte dos casos os agentes policiais provocaram lesões nos cidadãos de modo proporcional.

Relacionando a decisão judicial no âmbito penal com o perigo representado pela acção do cidadão, com a reacção do agente policial e com o crime imputado, concluiu-se o seguinte: (1) os agentes provocaram lesões de modo proporcional nos casos em que acção dos cidadãos representou perigo de ofensa simples à integridade física e perigo de ofensa grave à 
integridade física ou perigo de morte, nos casos em que a reacção dos agentes representou perigo de ofensa simples à integridade física e nos casos em que o crime imputado foi ofensas à integridade física; (2) os agentes provocaram lesões de modo não proporcional nos casos em que a acção dos cidadãos não representou qualquer perigo, nos casos em que a reacção dos agentes representou perigo de ofensa grave à integridade física ou perigo de morte e nos casos em que o crime imputado foi homicídio.

Palavras-chave: Lesão; dano corporal; meios coercivos; proporcionalidade; Polícia de Segurança Pública.

Summary: Injuries and harm resulting from the use of coercive measures by the Public Security Police

This study covers charges of the crimes of homicide and bodily harm brought against Public Security Police Officers during the course of duty, between 1991 and 2004.

The purpose of this study was to discover whether the injuries caused by the police officers were proportional to the danger posed by the actions of the citizens who were injured. In addition we characterized the injured parties, the assailing police officers and the circumstances in which the injuries were caused, and described the injuries and their after-effects and the penal, civil and disciplinary accountability attributed to the offending officers.

To achieve these objectives, we analysed the court rulings on 96 criminal proceedings brought against PSP officers for homicide or for bodily harm. These 96 proceedings provided us with 113 cases, each consisting of an "officer - injured party" pair.

The data was collected from several courts in mainland Portugal in which we were able to locate the criminal proceedings based on information from the Attorney General's Office. The data was collected onto a file containing the variables of interest for our study. The statistical analysis was carried out using the Statistical Package for the Social Sciences (SPSS) software, version 13.0.

We discovered that the injured parties were mostly young, single, employed males. Injuries were mostly caused by officers with the rank of Agente, at night, on the street, as a result of punching, kicking, slapping, discharging a firearm with live bullets and the use of a police truncheon. The danger posed to the police officers was lack of co-operation on the part of the citizens, leading the police officers to react in a way that afforded grievous bodily harm or death. The part of the body most affected was the face and in terms of seriousness, most injuries were classified as 1st degree and most after-effects as 0 degree. In the majority of the cases (54\%), the penal courts ruled for acquittal. Most civil courts also decided not to require indemnification.

An analysis of the relationship between the threat posed by the citizens and the police officers' reactions led us to conclude that in most cases the latter was disproportionate when the threat was either non-existent or when it consisted of non-collaboration or the possibility of bodily harm and was proportionate when the threat was of grievous bodily harm or was life-threatening. 
Taking only the penal court rulings into account, the conclusion was that in most cases the injuries inflicted by the police officers were proportional.

Upon articulating penal court decisions with the danger posed by the citizens' actions, the police officers' reaction and the crime the officers were accused of, we concluded that: (1) the injuries inflicted by the officers were proportional in situations in which the citizens' actions posed the threat of bodily harm, grievous bodily harm or life-threatening danger, in situations in which the police officers' reaction caused bodily harm and when the officers were accused with the crime of bodily harm; (2) the officers caused disproportionate injuries in situations in which the citizens' actions posed no threat, in situations in which the police officers' reaction resulted in grievous bodily harm or life-threatening danger and in situations in which the officers were accused with the crime of homicide.

Key-words: Injury; bodily harm; coercive measures; proportionality; Public Security Police.

Résumé: Blessures et dommages résultant de l'utilisation de méthodes coercitives par la Police de Sécurité Publique

Cette étude concerne les homicides et atteintes à l'intégrité physique imputés aux policiers de la sécurité publique dans l'exercice de leurs fonctions, entre 1991 et 2004.

On a prétendu par le biais de cette étude évaluer si les blessures causées par les policiers ont été proportionnelles au danger que représentaient les agissements des citoyens qui ont été victimes de ces atteintes. L'étude a également visé à caractériser les personnes victimes de ces atteintes, les policiers agresseurs et les circonstances dans lesquelles les blessures ont été provoquées, ainsi qu'à décrire les blessures et leurs séquelles et à calculer le niveau de responsabilité pénale, civile et disciplinaire des policiers ayant porté atteinte à l'intégrité physique des citoyens.

Afin d'atteindre ces objectifs, on a procédé à l'analyse des décisions judiciaires de 96 procédures pénales engagées contre des agents de la PSP pour homicide ou pour atteinte à l'intégrité physique. 113 cas ont été retirés de ces 96 procédures, chacun d'eux constitué par le binôme «police - victime».

La cueillette de données s'est réalisée dans divers tribunaux du Portugal continental, au sein desquels, grâce aux informations fournies par le bureau du Procureur général de la République, il a été possible de localiser les procédures pénales. Les données ont été recueillies dans une fiche contenant les variables qui présentaient un intérêt pour cette étude. L'analyse statistique a été faite en utilisant le logiciel Statistical Package for the Social Sciences (SPSS), version 13.0.

On a constaté que les citoyens ayant été victimes d'atteinte à leur intégrité physique étaient pour la plupart du sexe masculin, jeunes et célibataires, et qu'ils exerçaient une activité professionnelle. On a observé que les blessures avaient été pour la plupart provoquées par des policiers appartenant au corps d'Agente, la nuit, sur la voie publique, au travers de coups de poing, coups de pied, gifles, tirs d'armes à feux avec des projectiles létaux et coups de matraque, que le danger que représentaient les agissements des citoyens avait été la non-collaboration avec les agents et que la réaction de ceux-ci avait occasionné un 
danger d'atteinte grave à l'intégrité physique ou un danger de mort. On a constaté que la région corporelle la plus souvent atteinte était la face, que la gravité des blessures la plus fréquente correspondait au degré 1 et celle des séquelles au degré 0 . La décision judiciaire dans le cadre pénal a été, dans la plupart des cas (54\%), l'acquittement. De même, dans le cadre civil, la décision la plus fréquente a été la non-obligation d'indemniser la victime. L'analyse de la corrélation entre le danger que représentaient les agissements des citoyens et la réaction des policiers a permis de conclure que celle-ci avait été la plupart du temps disproportionnelle lorsque ledit danger était nul ou n'était autre que la non-collaboration ou encore la possibilité de survenance d'une atteinte simple à l'intégrité physique, et qu'elle avait été proportionnelle lorsqu'il existait un danger d'atteinte grave à l'intégrité physique ou un danger de mort.

En se restreignant aux résultats de la décision judiciaire dans le cadre pénal, on a constaté que, dans la plupart des cas, les policiers avaient provoqué des blessures aux citoyens de façon proportionnelle.

L'établissement d'une corrélation entre la décision judiciaire dans le cadre pénal et le danger que représentaient les agissements du citoyen, la réaction du policier ou encore l'infraction imputée a permis d'arriver à la conclusion suivante : (1) les policiers ont provoqué des blessures de façon proportionnelle dans les cas où les agissements des citoyens représentaient un danger d'atteinte simple à l'intégrité physique ou un danger d'atteinte grave à l'intégrité physique ou encore un danger de mort, dans les cas où la réaction des policiers représentait un danger d'atteinte simple à l'intégrité physique et dans les cas où l'infraction imputée était celle d'atteinte à l'intégrité physique ; (2) les policiers ont provoqué des blessures de façon disproportionnelle dans les cas où les agissements des citoyens ne représentaient aucun danger, dans les cas où la réaction des policiers représentait un danger d'atteinte grave à l'intégrité physique ou un danger de mort ainsi que dans les cas où l'infraction imputée était un homicide.

Mots-clés: Blessure; dommage corporel; méthodes coercitives; proportionnalité; Police de Sécurité Publique.

\section{PEDIDO DE SEPARATAS:}

EZEQUIEL RODRIGUES

ezrodrigues@gmail.com 